\title{
ANALISA BISNIS LIMBAH PADA CV.DUTA GEMILANG JAYA
}

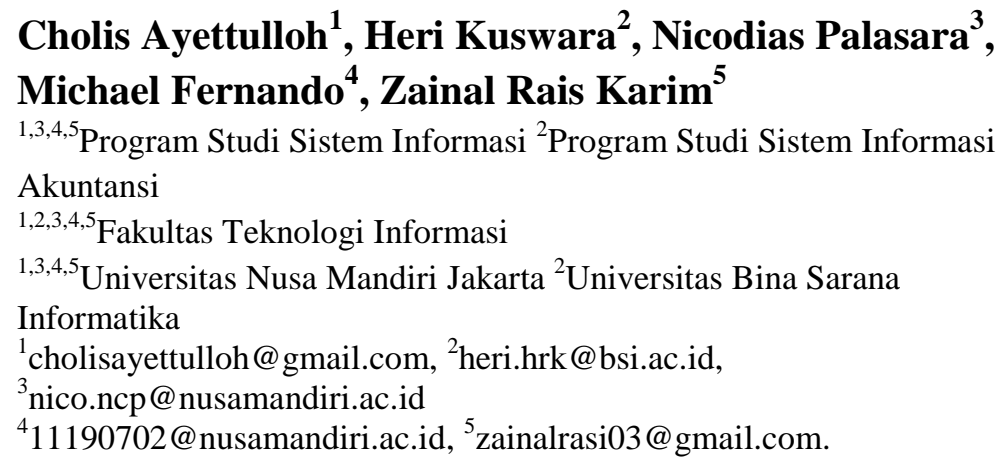

Received: February 15, 2021. Revised: April 15, 2021. Accepted: May 20, 2021. Published: June 20, 2021. Issue Period: Vol.5 No.1 (2021), Pp.99-110

\begin{abstract}
Abstrak--Meningkatnya jumlah limbah besi salah satunya dikarenakan daya hidup masyarakat yang menyukai kepraktisan,semua barang yang sudah tidak terpakai pada lingkungan pabrik yang sering kali hanya di buang begitu saja. Ini di karenakan tidak adanya tanggung jawab perusahaan,untuk menarik kembali produk bekas dari mereka yang sudah digunakan. Jika limbah yang tidak terpakai tersebut dibiarkan,tentu akan menimbulkan dampak serius bagi lingkungan disekitarnya. Disisi lain,barang bekas atau barang rongsok itu sebenernya masih bernilai jual yang relative tinggi. Dan semua barang bekas itu masih bisa dimanfaatkan .Rongsokan tersebut nantinya didaur ulang untuk di jadikan benda yang lainnya.Dengan meningkatnya pertumbuhan Industri tersebut salah satunya berupa limbah Scrab,Besi Batangan,Drum Dll yang secara fisik menyerupai Besi. Saat ini sudah banyak barang pengepul bekas ataupun barang rongsokan disetiap daerah termasuk di kota Jakarta.Para pengepul tersebut biasanya ada yang mengambil barang dari perusahaan ataupunada yang mengirim barang ke pengepul.Oleh karena itu Scrab,Besi Batangan, Drum Dll tersebut perlu ditangani dengan tepat. Berdasarkan hal tersebut perlu adanya suatu penelitian untuk pemanfaatan limbah Industri. Dari barang yang dapat merusak lingkungan,menjadi sesuatu yang dapat dimanfaatkan sebagai komuditi atau bahan tambahan.
\end{abstract}

Kata Kunci : limbah besi, lingkungan,industri, perusahaan.

Abstrak- The increase in the amount of iron waste, one of which is due to the life force of the
people who like practicality, all items that are not used in the factory environment are often
just thrown away. This is due to the absence of company responsibility, to withdraw used
products from those that have been used. If the unused waste is left alone, it will certainly have
serious impacts on the surrounding environment. On the other hand, used goods or wrecked
goods still have relatively high selling value. And all the used goods can still be used. The junk
will later be recycled to make other objects. With the increasing growth of the industry, one of
them is in the form of Scrab, Iron Bar, Drum etc. which physically resembles Iron. Currently

DOI: $10.52362 /$ jisicom.v5i1.388

Ciptaan disebarluaskan di bawahLisensi Creative Commons Atribusi 4.0 Internasional. 
Journal of Information System, Informatics and Computing

Website/URL: http://journal.stmikjayakarta.ac.id/index.php/jisicom

Email: jisicom@stmikjayakarta.ac.id ,jisicom2017@gmail.com

\begin{abstract}
there are many used or junk goods in every area, including in the city of Jakarta. The collectors usually take goods from companies or send goods to collectors. Therefore, Scrab, Iron Bar, Drum Etc. need to be handled appropriately. . Based on this, it is necessary to have a research for the utilization of industrial waste. From items that can damage the environment, into something that can be used as commodities or additional materials.
\end{abstract}

Key words: iron waste, environment, industry, company

\title{
I. PENDAhuluaN
}

\subsection{Latar Belakang}

Limbah merupakan salah satu jenis bahan yang di hasilkan dari suatu proses produksi. Limbah dapat dikategorikan menjadi barang yang dapat membahayakan lingkungan dan tidak membahayakan lingkungan. Pengertian limbah berdasarkan keputusan Menperindag RI No. 231/MPP/Kep/7/1997 Pasa1 tentang prosedur impor limbah, menyatakan bahwa "limbah adalah bahan/barang sisa atau bekas dari suatu kegiatan atau proses produksi yang fungsinya sudah berubah dari aslinya"[1]. Sedangkan berdasarkan Peraturan Pemerintah No. 18/1999 Jo PP 85/1999, limbah didefinisikan sebagai sisa atau buangan dari suatu usaha dan / atau kegiatan manusia". Perkembangan industri bidang material dan metalurgi nasional pun semakin berkembang pesat di Indonesia.Sebagai contoh,industri baja nasional pun semakin berkembang dari tahun ke tahun. Limbah yang membahayakan lingkungan harus dapat dikelola dan ditangani secara khusus agar tidak berbahaya terhadap kelestarian lingkungan hidup[2]. Meningkatnya jumlah limbah besi salah satunya dikarenakan daya hidup masyarakat yang menyukai kepraktisan,semua barang yang sudah tidak terpakai pada lingkungan pabrik yang sering kali hanya di buang begitu saja. Ini di karenakan tidak adanya tanggung jawab perusahaan,untuk menarik kembali produk bekas dari mereka yang sudah digunakan. Jika limbah yang tidak terpakai tersebut dibiarkan,tentu akan menimbulkan dampak serius bagi lingkungan disekitarnya[3]. Disisi lain,barang bekas atau bisa disebut barang rongsok itu sebenernya masih bernilai jual yang relative tinggi. Dan semua barang bekas itu masih bisa dimanfaatkan .Rongsokan-rongsokan tersebut nantinya didaur ulang untuk di jadikan benda yang lainnya.

Pemanfaatan rongsokan untuk di daur ulang sangat baik untuk lingkungan,karena dengan memanfaatkan barang-barang tersebut dapat mengurangi pencemaran lingkungan sekitarnya.Saat ini sudah banyak barang pengepul bekas ataupun barang rongsokan di setiap daerah termasuk di kota Jakarta.Para pengepul tersebut biasanya ada yang mengambil barang dari perusahaan ataupun ada yang mengirim barang ke pengepul. Di pengepulan rongsok barang-barang tersebut,dipilah pilih sesuai dengan jenisnya,dari jenis rongsok-rongsok antara lain adalah besi bekas.Mungkin hanya terlihat biasa bagi orang yang kurang memahaminya,tapi sebenarnya besi bekas dapat dijadikan sebagai peluang bisnis.Karena besi bekas dapat di olah kembali menjadi wujud yang lainnya dengan dilakukan Di daur ulang ataupun dapat dilebur .Dengan meningkatnya pertumbuhan Industri tersebut salah satunya berupa limbah Scrab,Besi Batangan,Drum Dll yang secara fisik menyerupai Besi.

Oleh karena itu Scrab,Besi Batangan, Drum Dll tersebut perlu ditangani dengan tepat. Berdasarkan hal tersebut perlu adanya suatu penelitian untuk pemanfaatan limbah Industri. Dari barang yang dapat merusak lingkungan,menjadi sesuatu yang dapat dimanfaatkan sebagai komuditi atau bahan tambahan. Penelitian ini ditujukan untuk menemukan kegunaan dari limbah padat Scrab,Besi Batangan,Drum Dll sehingga dapat dimanfaatkan sebagai bahan campuran pembuatan Kursi,Meja,Pagar Besi,Lemari Hias dan Tempat Pot Besi.

\subsection{Identifikasi Masalah} berikut:

Berdasarkan identifikasi masalah di atas,maka permasalahan yang terjadi dapat di identifikasi sebagai

a. Penggunaan bahan dan alat-alat terhadap aktivitas yang dilakukan apabila tidak diolah dengan baik dapat menghasilkan limbah yang dapat mencemari lingkungan sekitarnya[4].

DOI: $10.52362 /$ jisicom.v5i1.388

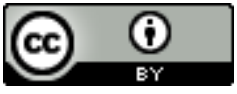

Ciptaan disebarluaskan di bawahLisensi Creative Commons Atribusi 4.0 Internasional. 
Website/URL: http://journal.stmikjayakarta.ac.id/index.php/jisicom

Email: jisicom@stmikjayakarta.ac.id ,jisicom2017@gmail.com

b. Bahan limbah hasil dariPerusahaan Engineering adalah umumnya berbahaya dan tidak boleh dibuang secara sembarangan.

c. Perlu dilakukan cek rutin secara berkala pada tempat pembuangan limbah tersebut sehingga tidak mencemari lingkungan setempat.

d. Barang yang berupa produk scrab,besi batangan,drum yang semakin banyak di dapat di Industry limbah tersebut.

e. Menciptakan produk daur ulang yang inovatif dari limbah besi

f. Menciptakan peluang usaha dengan inovasi produk daur ulang limbah besi.

1.3. Tujuan dan Manfaat

a. Agar dapat mencontohkan kepada masyarakat ke daerah setempat dan mensejahterakan secara ekonomi dengan adanya membangun usaha yang kreatif dan inovatif agar kedepannya semakin berkembang.

b. Dengan adanya menghasilkan produk berupa kursi,asbak,pager besi dan meja yang berbahan dari dasar besi bekas,dapat diharapkan memiliki beberapa manfaat yang bisa kita ambil seperti mengurangi limbah besi hasil dari pembuangan besi limbah pabrik.Kursi yang terbuat dari besi batangan tersebut dapat juga mengurangi penggunaan dari limbah yang tidak terpakai selain itu,dapat menciptakan peluang usaha baru bagi masyarakat,dapat menekankan jumlah angka pengangguran di dalam masyarakat ataupun di luar masyarakat.

1.4. Luaran yang diharapkan

Luaran yang hendak dicapai dalam analisa ini adalah :

1. Meningkatkan kreativitas inovatif mahasiswa dan masyarakat dalam rangka bereksperimen serta menemukan hasil karya yang bermanfaat dan tepat guna[5].

2. Tercapainya penjualan barang kepada para konsumen.

3. Dari Barang limbah yang berupa produk scrab,besi batangan dan drum yang di daur ulang dapat menghasilkan seperti Kursi,Meja,Pagar Besi,Lemari Hias dan Tempat Pot Besi.

\section{METODE PENELITIAN}

Scrab adalah sebuah limbah yang memanfaatkan besi sebagai bahan bakunya. Alasan digunakannya scrab sebagai bahan baku adalah karena besi mudah diperoleh, dan banyak dijumpai di sekeliling kita [6]. Strategi pengembangan usaha dilakukan dengan pengenalan produk kepada masyarakat dengan cara sosialisasi baik pada konsumen pasar maupun home industry. Rekruitmen tenaga kerja dilakukan secara langsung dengan mempertimbangkan seberapa besar minat dan loyalitas tenaga kerja dalam berwirausaha demi tercapainya target usaha, yaitu memproduksi produk yang berkualitas dan diterima pasar. Pertama yang dilakukan pada saat tahap penelitian yaitu survey pasar yang dilakukan sebagai langkah awal dalam memulai sebuah usaha. Tujuan dilakukannya survei adalah untuk mengetahui kondisi pasar, minat konsumen, dan perencanaan inovasi lebih lanjut[7].

\subsection{Analisa}

Analisa sistem dapat didefinisikan sebagai penguraian dari suatu sistem informasi yang utuh ke dalam bagian-bagian komponen dengan maksud untuk mengidentifikasikan dan mengevaluasi permasalahanpermasalahan, dan hambatanhambatan yang terjadi dan kebutuhan-kebutuhan yang diharapkan sehingga dapat diusulkan perbaikannya[8].

Pengertian analisis adalah kegiatan berpikir untuk menguraikan suatu keseluruhan menjadi komponen sehingga dapat mengenal tanda-tanda komponen, hubungannya satu sama lain dan fungsi masing-masing dalam satu keseluruhan yang terpadu[9].

Pengertian analisis adalah memecahkan atau menguraikan sesuatu unit menjadi unit terkecil. Dari pendapat diatas dapat ditarik kesimpulan bahwa analisis merupakan suatu kegiatan berfikir untuk menguraikan atau memecahkan suatu permaslaahan dari unit menjadi unit terkecil. Analisis merupakan sebuah kegiatan untuk meneliti suatu objek tertentu secara sistematis, guna mendapatkan informasi mengenai objek tersebut, sebagai

DOI: $10.52362 /$ jisicom.v5i1.388

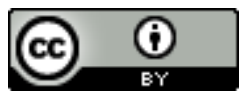

Ciptaan disebarluaskan di bawahLisensi Creative Commons Atribusi 4.0 Internasional. 


\section{Journal of Information System, Informatics and Computing}

Website/URL: http://journal.stmikjayakarta.ac.id/index.php/jisicom

Email: jisicom@stmikjayakarta.ac.id ,jisicom2017@gmail.com

contoh dalam dunia bisnis, pihak manajemen dalam sebuah perusahaan melakukan analisis untuk mendapatkan informasi mengenai target pasar, produk yang akan dibuat, strategi pemasaran dan lain sebagainya.

analisis adalah suatu kegiatan atau proses berfikir untuk membagi dan menguraikan sesuatu secara keseluruhan menjadi bagian dari komponen yang berbeda sehingga tanda-tanda dan ciri dari setiap komponen bisa dikenal, dan dihubungkan satu sama lainnya. Masing-masing komponen memiliki fungsi yang berbeda dan jika disatukan menjadi satu keseluruhan yang saling terpadu[10].

\subsection{Analisa Pemasaran}

Jenis produk ini berupa limbah Scrab dengan bahan dasar besi. Produk yang disalurkan oleh program ini memiliki kualitas yang bagus serta harga yang sangat

terjangkau.Untuk menunjang proses pemasaran,ada bebearap alternative yang bisa digunakan, sehingga lebih dikenal oleh masyarakat dan menjadi pilihan masyarakat. Media ini berupa, media elektronik dan media surat.Kami akan mengaitkan produk kami dengan menyadari pentingnya cinta lingkungan sejak dini, dengan cara membeli produk pengolahan limbah besi ini, agar limbah besi semakin berkurang, dan lingkungan semakin membaik dan manusia semakin sehat.

\begin{tabular}{|c|l|l|}
\hline \multicolumn{3}{|c|}{ SEGMENTASI PASAR } \\
\hline \multirow{2}{*}{ Dimensi Utama } & \multicolumn{1}{|c|}{ Variabel } & \\
\hline \multirow{2}{*}{ Segmentasi Geografis } & Wilayah Negara & Indonesia \\
\cline { 2 - 3 } & Wilayah Daerah & Jakarta dan sekitamya \\
\hline \multirow{2}{*}{ Segmentasi Demografis } & Umur & 17 sampai 55 Tahun \\
\cline { 2 - 3 } & Jenis Kelamin & Laki-laki dan perempuan \\
\hline \multirow{2}{*}{ Segmentasi Psikografis } & Gaya Hidup & Unik, cerdas, kreativ, praktis dan ekonomis \\
\cline { 2 - 3 } & Kepribadian & Mencintai lingkungan sejak dini \\
\hline \multirow{2}{*}{ Segmentasi Pasar } & Benefit & $\begin{array}{l}\text { Mengurangi limbah besi scrab,besi batangan dan } \\
\text { drum dengan mendaur ulang }\end{array}$ \\
\hline
\end{tabular}

Tabel 1. Analisa Pasar Dari Produk

\subsection{Analisis SWOT}

Dalam penelitian ini penelitian akan di analisis secara dekskriptip kualitatip selain itu penulis juga menggunakan analisis SWOT[11] Matriks SWOT merupakan alat-alat yang di pakai untuk mengukur faktor faktor strategi perusahaan. Matriks ini dapat menggambarkan secara jelas bagaimana peluang dan ancaman eksternal yang dimiliki. Matriks ini dapat menghasilkan empat sel kemungkinan alternatif strategi yang dapat dilihat.Berdasarkan analisis diatas menunjukan bahwa kinerja perusahaan dapat ditentukan oleh kombinasi faktor internal dan eksternal, kombinasi kedua faktor tersebut di tunjukan dalam diagram hasil analisis SWOT sebagai berikut:

\section{Strategi SO(Strenght-Opportunity)}

Strategi ini merupakan gabungan dari faktor internal (Strenght) dan faktor eksternal (Opportunity), strategi ini dibuat berdasarkan pemikiran dengan memanfaatkan seluruh kekuatan untuk merebut dan memanfaatkan peluangsebesar-besarnya. Strategi SO yang di tempuh Usaha Pengrajin pot bunga asbak, meja dll yaitu:

a. Mempertahankan kualitas ketebalan pot bunga,asbak, meja dll tahan lama, dantidak berkarat.

b. Meningkatkan produksi yang efektif untuk memenuhikebutuhan pelanggan.

\section{Strategi ST(Strenght-Threat).}

Strategi ini merupakan gabungan dari faktor internal (Strenght) dan faktor eksternal (Threat), strategi ini menggunakan kekuatan yang dimiliki peusahaan untuk mengatasi segala ancaman dari luar. Strategi ST yang ditempuh Usaha Pengrajin pot bunga,asbak, kursi dll yaitu:

a. Mempertahankan kualitas ketebalan pot bunga asbak kursi dll, tahan lama, dan tidak berkarat.

b. Menetapkan dan mempertahan harga pasar yang bersaing.

DOI: $10.52362 /$ jisicom.v5i1.388

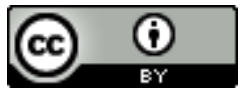

Ciptaan disebarluaskan di bawahLisensi Creative Commons Atribusi 4.0 Internasional. 
e-ISSN : 2597-3673 (Online), p-ISSN : 2579-5201 (Printed)

Vol.5 No.1, Juni 2021

Journal of Information System, Informatics and Computing

Website/URL: http://journal.stmikjayakarta.ac.id/index.php/jisicom

Email: jisicom@stmikjayakarta.ac.id,jisicom2017@ gmail.com

c. Mempertahankan bahan baku yang berkualitas untuk menghasilkan produk yang baik dan unggul.

\section{Strategi WO (Weakness-Opportunity)}

Strategi ini merupakan gabungan dari faktor internal (Weakness) dan Faktor eksternal (Opportunity), strategi ini diterapkan berdasarkan pemanfaatan peluang yang ada dengan cara mengurangi kelemahan yang dimiliki oleh perusahaan strategi WO yang diterapkan oleh Usaha Pengrajin asbak yaitu:

a. Meningkatkan promosi dengan memanfaatkan mediasosial.

b. Menambah mitrakerja.

\section{Strategi WT (Weakness-Threat)}

Strategi ini merupakan gabungan dari faktor internal (Weaknes) dan faktor eksternal (Threat), strategi ini didasarkan pada aktivitas yang sifatnya defensive dan berusaha menghindari kemungkinan adanya ancaman dari luar untuk untuk mengurangi kelemahan perusahaan. Strategi WO yang ditempuh oleh Usaha Pengrajin asbak yaitu:

a. Memberikan bahan baku yang benar-benar aman untukdipakai

b. Mempertahankan hubungan baik dengan pelanggan ataukonsumen

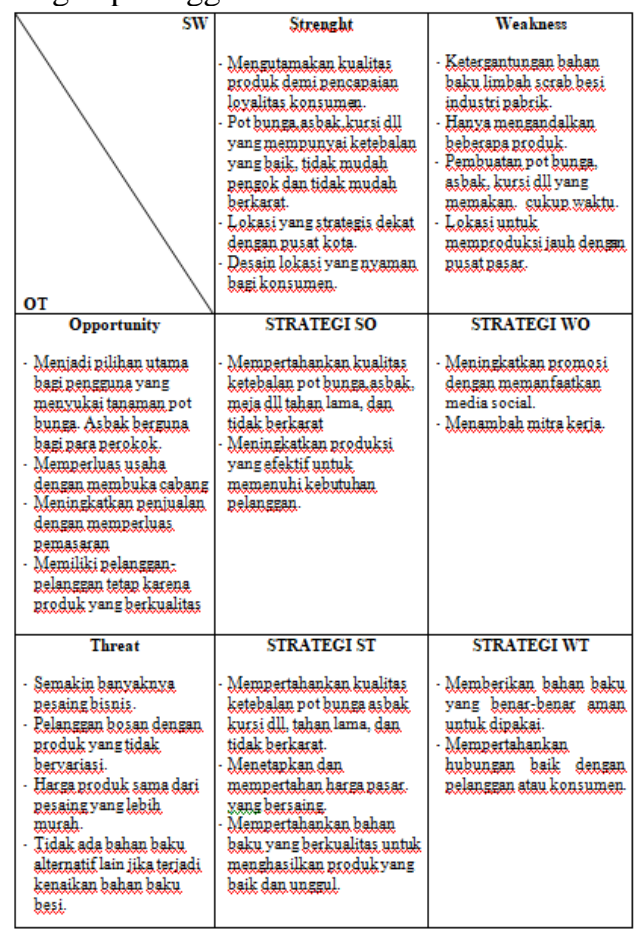

Tabel 2. SWOT

2.4. Matrik IFAS (Internal Factor Assesment Strategy)

Menurut David, ada beberapa tahap penyususunan Matriks Internal factorAssesment Strategy (IFAS)[12] yaitu:

a. Tentukan faktor-faktor yang menjadi kekuatan dan kelemahan

b. Beri bobot masing-masing faktor mulai dari 1,0 (sangat penting) sampai0,0 (tidak penting). Bobot yangdiberikan kepada masing-masing faktor mengidentifikasi tingkat penting relatif dari faktor terhadap keberhasilan perusahaan dalam suatu industri. Tanpa memandang apakah kunci itu adalah kekuatan atau kelemahan internal, faktor yang diangap memiliki pengaruh besar dalam kinerja organisasi harusdiberikan bobot yang tinggi.Jumlah seluruh bobot harus samadengan 1,0 .

DOI: $10.52362 /$ jisicom.v5i1.388

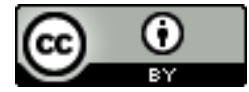

Ciptaan disebarluaskan di bawahLisensi Creative Commons Atribusi 4.0 Internasional. 
e-ISSN : 2597-3673 (Online), p-ISSN : 2579-5201 (Printed)

Journal of Information System, Informatics and Computing

Website/URL: http://journal.stmikjayakarta.ac.id/index.php/jisicom

Email: jisicom@stmikjayakarta.ac.id ,jisicom2017@gmail.com

c. Berikan rating 1 samapi 4 bagi masing-masing faktor untuk menunjukan apakah faktor tersebut memiliki kelemahan yang besar (rating = 1), kelemahan yang kecil (rating = 2), kekuatan yang kecil (rating = 3), dan kekuatan yangbesar ( rating $=4$ ).Jadi sebenarnya rating mengacu pada perusahaan sedangkan bobot mengacu pada industri dimana perusahaan berada.

d. Kalikan masing-masing bobot dengan ratingnya untuk mendapatkan score.

e. Jumlahkan total skor masing-masingvariabel.

Berapapun banyaknya faktor yang dimasukkan dalam faktor IFAS, total rata-rata tertimbang berkisar antara yang rendah 1,0 dan tertinggi 4,0 dengan rata-rata 2,5, jila rata-rata dibawah 2,5 menandakan secara internal perusahaan lemah, sedangkan total nilai diatas 2,5 mengingindikasikan posisi internal yang kuat.

\subsection{Matriks EFAS (Eksternal Factor AssesmentStrategy)}

Menurut David, ada beberapa tahap penyususunan Matriks Internal factorAssesment Strategy (EFAS)[12] yaitu:

a. Tentukan faktor-faktor yang menjadi peluang dan ancaman

b. Beri bobot masing-masing faktor mulai dari 1,0 (sangat penting) sampai 0,0(tidak penting). Faktor-faktor tersebut kemungkinan dapat memberikan dampak terhadap faktor strategis. Jumlah seluruh bobot harus sama dengan1,0.

c. Menghitung rating untuk masing-masing faktor dengan memberikan skala mulai1 samapi 4, dimana 4 (respon sanga bagus, 3 (respon di atas rata-rata), 2 (respon rata-rata), 1 (respon diatas rata-rata), rating ini berdasarkan padaefektifitas strategi perusahaan, dengan demikian nilai berdasarkan pada kondisi perusahaan.

d. Kalikan masing-masing bobot dengan ratingnyauntuk mendapatkanscore.

Jumlah semua skor untuk mendapatkan nilai total score perusahaan. Nilai total ini menunjukan bagaimana perusahaan tertentu bereaksi terhadap faktor-faktorstrategis eksternalnya. Sudah tentu bahwa dalam EFAS Matrix, kemungkinan nilai tertinggi total score adalah 4,0 dan terendah adalah 1,0. Total score 4,0 mengindikasikan bahwa perusahaan meresponpeluang yang ada dengan cara yang luar biasa dan meghindari ancaman-ancaman dipasar industrinya. Total score sebesar 1,0 menunjukan srategi-strategi perusahaan tidak memanfaatkan peluang-peluang atau tidak menghindari ancaman-ancamaneksternal. Dari hasil analisis EFAS faktor peluang dan mengidentifikasikan bahwa perusahaan merespen peluang yang ada dengan cara luar biasa dan menghidari ancaman-ancaman di pasar industri.

Berdasarkan dari hasil matriks IFAS dan Matriks EFAS. Diketahui dengan demikian Usaha Pengrajin Pot Bunga,Asbak, Meja dll. Dengan dapat diketahui strategi yang dapat digunakan adalah strategi pertumbuhan melalui integrasi horisontal strategi adalah suatu kegiatan untuk memperluas Usaha Pengrajin pot bunga, asbak meja dll dengan cara mempertahankan kualiatas pot bunga,asbak,meja dll dan meningkatkan produksi yang efektif untuk memenuhi kebutuhan pelanggan.Karena Usaha Pengrajin pot bunga,asbak,meja dll berada dalam daya tarik sedang, strategi yang diterapakan adalah konsolidasi. Tujuannya relatif lebih defensif, yaitu menghindari kehilangan pelanggan. Usaha Pengrajin pot bunga,asbak,meja dll yang berada disel ini dapat memperluas strategi pengembangan usaha yang baik, dan melalui pengembangan internal daneksternal.

\subsection{Diagram Cartesius Analisis SWOT}

Menunjukan bahwa Usaha Pengrajin pot bunga,asbak,kursi dll berada Pada Kuadran growt dimana kuadran tersebut merupakan situasi yang sangat menguntungkan perusahaan tersebut memiliki peluang dan kekuatan, sehingga dapat memanfaatkan peluang yang ada, strategi yang harus diterapkan dalam kondisi ini adalah mendukung kebijakan pertumbuhan yang agresif (Growth Oriented Strategy). Kebijkan pertumbuhan yang agresif dapat disimpulkan sebagai suatu pemikiran yang logis, konseptualisasi hal-hal prioritas (Dalam jangka panjang maupun pendek) untuk dijadikan acuan untuk menentukan langkah ataupun tindakan yang akan dilakukan. Strategi pertumbuhan yang agresif dapat dimulai dengan memberikan pelayanan yang baik kepada konsumen serta memenuhi kebutuhan pelanggan.

\section{III.HASIL DAN PEMBAHASAN}

DOI: $10.52362 /$ jisicom.v5i1.388

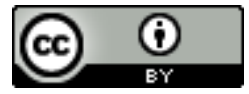

Ciptaan disebarluaskan di bawahLisensi Creative Commons Atribusi 4.0 Internasional. 
e-ISSN : 2597-3673 (Online), p-ISSN : 2579-5201 (Printed)

Vol.5 No.1, Juni 2021

Journal of Information System, Informatics and Computing

Website/URL: http://journal.stmikjayakarta.ac.id/index.php/jisicom

Email: jisicom@stmikjayakarta.ac.id, jisicom2017@gmail.com

\subsection{Pengelolaan Usaha Limbah Besi Industri}

Usaha Pengolahan limbah Besi yang di kelola oleh Bapak Cholis Ayetulloh berawal dari keinginan beliau untuk membuat suatu usaha karena melihat adanya peluang usaha didaerah tersebut.Tenaga kerja Usaha Pengolahan limbah Besi ada yang berasal dari daerah tersebut dan ada juga yang berasal dari luar daerah.Bahan baku yang digunakan adalah limbah besi yang sudah tidak terpakai seperti pager rumah atau potongan besi tergantung pada stok yang ada.Stok besi sering kehabisan yang menyebabkan bapak Cholis Ayetulloh terkadang beralih kepada limbah besi yang lainnya yang harganya lebih mahal, selain itu limbah yang di hasilkan besi pengepul tidak sebagus hasil besi yang sudah terpakai sehabis pengolahan industri.Untuk modal awal mendirikan usaha Pengolahan limbah Besi yaitu Rp. 500.000.000,00 yang mana modal tersebut digunakan untuk membeli mesin, membuat bangunan semi permanen untuk memproduksi pot bunga, asbak, kursi dan lain-lain.

Cara pengelolaan limbah besi adalah sebagai berikut:

a. Besi-besi yang telah tidak terpakai di kumpulkan

b. Setelah itu mengambil sebagian besi untuk dipotong mejadi beberapa bagian.

c. Kemudian di bentuk lah sebagian dari besi yang telah di potong.

d. Setelah di bentuk akan menjadi seperti pot bunga, tempat sampah, pagar besi dll. Tergantung pemesanan dari konsumen.

Dari uraian diatas dapat diketahui bahwa dalam pembuatan pot bunga, asbak,kursi dll hanya menggunakan bahan baku yaitu berupa besi limbah industri tanpa komposisi lainnya, namun juga untuk mengurangi menumpuknya limbah scrab besi akibat pemanfaatannya yang sangat terbatas[11].Usaha Pengrajin pot bunga, asbak, kursi dll Tidak Mengguanakan bahan campuran yang berbahaya dalam memproduksi pot bunga, asbak, kursi dll nya, maka dari itu pot bunga, asbak, kursi dll baik digunakan dalam jangka waktu yang lama. yang di produksi Usaha Pengrajin pot bunga, asbak kursi dll akan dipasarkan dengan harga Rp. 100.000/ satuanya.

\section{Biaya Tetap Dalam 1 Perbulan}

\begin{tabular}{|c|c|c|}
\hline Nama Barang & Kontribusis! & Total \\
\hline Gajl Pegagaval & Sorang x Rp 100.000,00 x + kali juadan. & Rpl.200.000 \\
\hline Serva tempat & . & \\
\hline Total & & Rpl.200.000 \\
\hline
\end{tabular}

Tabel 3. Biaya Tetap dalam 1 Perbulan

\section{Biaya Variable dalam 1 Perbulan}

\begin{tabular}{|c|c|c|}
\hline Nama Barang & Kontribusi & Total \\
\hline Besi & $\mathrm{Rp} 5000 \mathrm{~kg} \times 2670 \mathrm{~kg}$ & $\operatorname{Rp} 13.350 .000,00$ \\
\hline Gas & $250.000,00 \times 4$ & Rp 1.000.000,00 \\
\hline Tranpottasi & 4kali jualan $\times 2$ orang $x$ Rp 200.000,00 & Rp 800.000,00 \\
\hline Total & & $\operatorname{Rp} 15.150 .000,00$ \\
\hline
\end{tabular}

Tabel 4. Variable dalam 1 Perbulan

\section{Omset $=$ Uang Masuk Penjualan dalam 1 Bulan}

DOI: $10.52362 /$ jisicom.v5i1.388

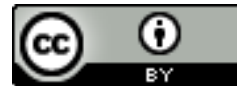

Ciptaan disebarluaskan di bawahLisensi Creative Commons Atribusi 4.0 Internasional. 
e-ISSN : 2597-3673 (Online) , p-ISSN : 2579-5201 (Printed)

Vol.5 No.1, Juni 2021

Journal of Information System, Informatics and Computing

Website/URL: http://journal.stmikjayakarta.ac.id/index.php/jisicom

Email: jisicom@stmikjayakarta.ac.id ,jisicom2017@ gmail.com

\begin{tabular}{|c|c|c|c|}
\hline Produk & Jumlah terjual & Harga per buah & Total \\
\hline Kursi & 10 & $\operatorname{Rp} 250.000,00$ & $\operatorname{Rp} 2.500 .000,00$ \\
\hline Meja & 10 & Rp 100.000,00 & $\operatorname{Rp} 1.000 .000,00$ \\
\hline Pagar Besi & 7 & Rp 1.000.000,00 & Rp 7.000.000,00 \\
\hline Asbak & 1.500 & Rp $5.000,00$ & Rp 7.500.000,00 \\
\hline Pot Besi & 20 & Rp 100.000,00 & Rp 20000.000,00 \\
\hline Total & & & Rp20.000.000,00 \\
\hline
\end{tabular}

Tabel 5. Uang Masuk Penjualan dalam 1 Bulan

4. Lampiran 1

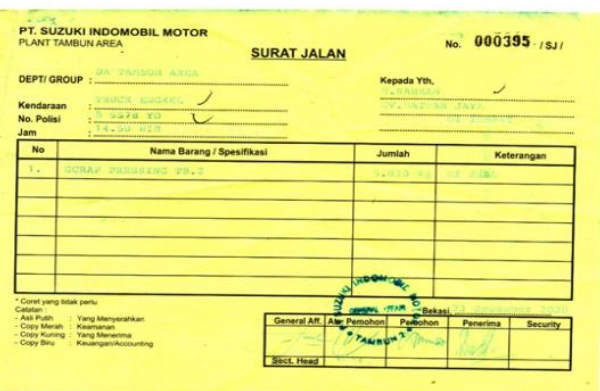

Gambar 1. Lembar Surat Jalan

5. Lampiran 2

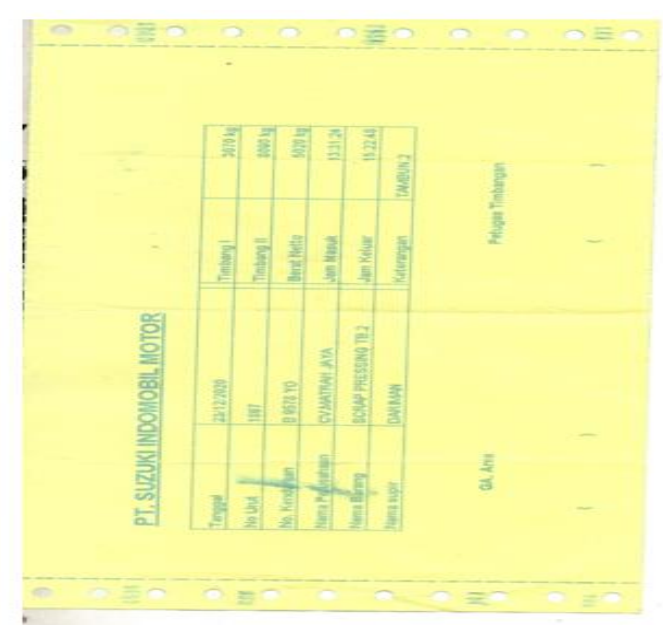

Gambar 2. Lembar Surat Jalan

DOI: $10.52362 /$ jisicom.v5i1.388

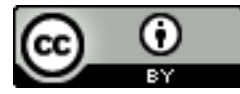

Ciptaan disebarluaskan di bawahLisensi Creative Commons Atribusi 4.0 Internasional. 
e-ISSN : 2597-3673 (Online), p-ISSN : 2579-5201 (Printed)

Vol.5 No.1, Juni 2021

Journal of Information System, Informatics and Computing

Website/URL: http://journal.stmikjayakarta.ac.id/index.php/jisicom

Email: jisicom@stmikjayakarta.ac.id,jisicom2017@ gmail.com

6. Lampiran 3

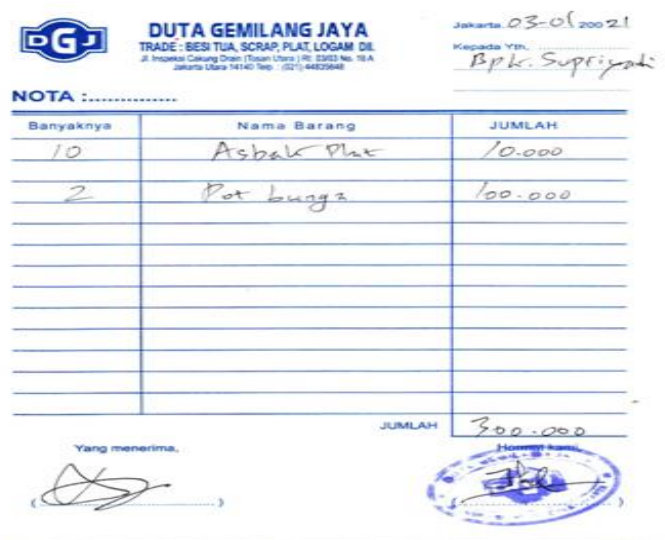

Gambar 3. Lembar Nota Pembelian

7. Lampiran 4

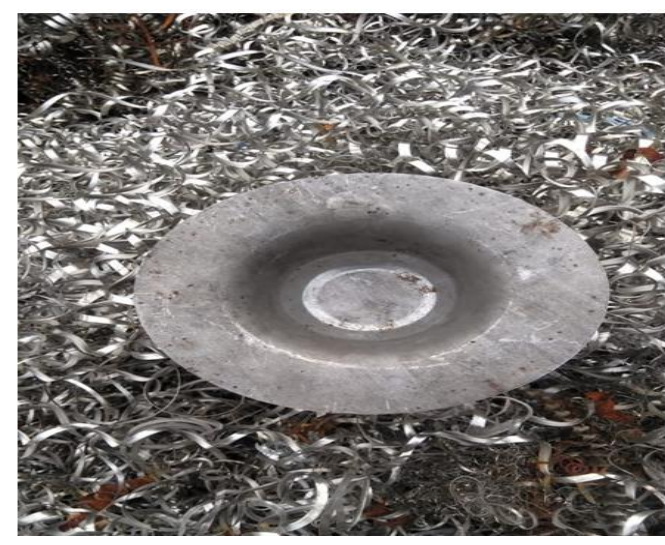

Gambar 4. Asbak Rokok

DOI: $10.52362 /$ jisicom.v5i1.388

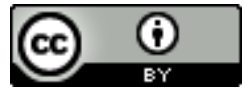

Ciptaan disebarluaskan di bawahLisensi Creative Commons Atribusi 4.0 Internasional. 
e-ISSN : 2597-3673 (Online) , p-ISSN : 2579-5201 (Printed)

Vol.5 No.1, Juni 2021

Journal of Information System, Informatics and Computing

Website/URL: http://journal.stmikjayakarta.ac.id/index.php/jisicom

Email: jisicom@stmikjayakarta.ac.id,jisicom2017@ gmail.com

8. Lampiran 5

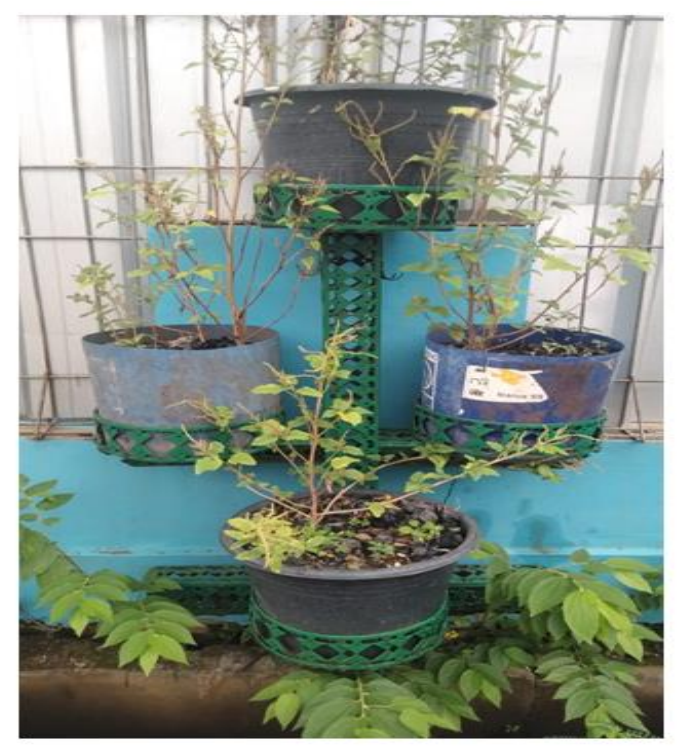

Gambar 5 Pot Bunga

9. Lampiran 6

DOI: $10.52362 /$ jisicom.v5i1.388

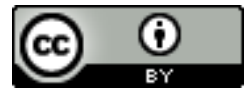

Ciptaan disebarluaskan di bawahLisensi Creative Commons Atribusi 4.0 Internasional. 
e-ISSN : 2597-3673 (Online) , p-ISSN : 2579-5201 (Printed)

Vol.5 No.1, Juni 2021

Journal of Information System, Informatics and Computing

Website/URL: http://journal.stmikjayakarta.ac.id/index.php/jisicom

Email: jisicom@stmikjayakarta.ac.id ,jisicom2017@ gmail.com

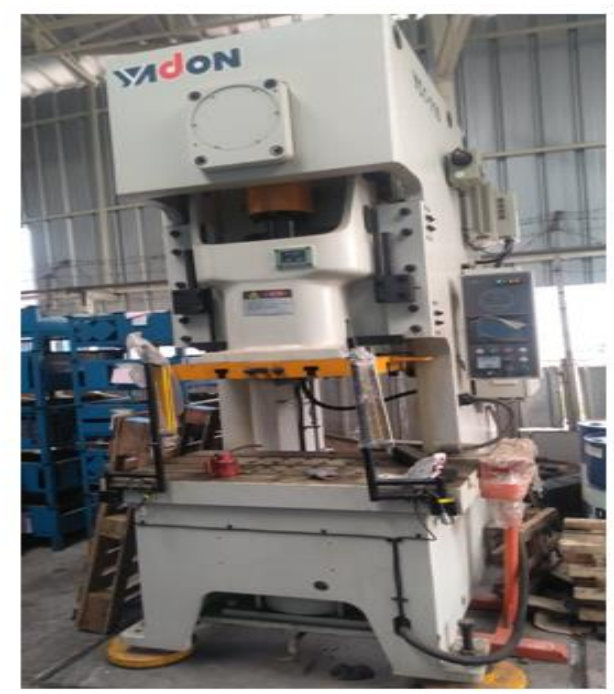

Gambar 6 Mesin Pressing

\section{IV.KESIMPULAN}

Berdasarkan hasil pengolahan data dan pembahasan dapat di peroleh kesimpulan dari penelitian sebagai berikut :

1. penanganan limbah bahan berbahaya dapat ditanggulangi dengan pengurangan penggunaan limbah scrab besi yang berlangsung dengan baik,dengan adanya proses kegiatan mendaur ulang limbah scrab besi menjadi barang yang menjadi bisa digunakan untuk semua kalangan seperti pot bunga ,pager,kursi,meja dan lain-lain.

2. dapat memberikan pembenahan pada kesehatan lingkungan secara optimal,bagi masyarakat sekitar.

3. Memberikan pembenahan kepada kesehatan lingkungan dalam mingkatkan kegiatan daur ulang dalam pengolahan limbah.

\section{SARAN}

1. Meningkatkan proses produksi, sehingga dapat meningkatkan laba usaha.

2. Mencari mitra kerja guna meningkatkan memajukan usaha.

3. Menjaga Konsumen agar tidak kecewa dalam membeli barang kepada kita.

4. Dalam Analisa Skripsi ini dapat merubah penglolaan limbah yang lebih optimal lagi.

5. Menjaga Kualitas produk agar tidak mengecewakan kepada pelanggan.

\section{REFERENSI :}

[1] A. Çelik et al., “No 主観的健康感を中心とした在宅高齢者における健康関連指標に関する共分散構造 分析Title,” J. Mater. Process. Technol., vol. 1, no. 1, pp. 1-8, 2018, [Online]. Available:

http://dx.doi.org/10.1016/j.cirp.2016.06.001\%0Ahttp://dx.doi.org/10.1016/j.powtec.2016.12.055\%0Ahttps://doi .org/10.1016/j.ijfatigue.2019.02.006\%0Ahttps://doi.org/10.1016/j.matlet.2019.04.024\%0Ahttps://doi.org/10.10

DOI: $10.52362 /$ jisicom.v5i1.388

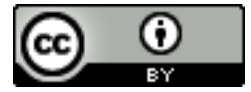

Ciptaan disebarluaskan di bawahLisensi Creative Commons Atribusi 4.0 Internasional. 
e-ISSN : 2597-3673 (Online) , p-ISSN : 2579-5201 (Printed)

Vol.5 No.1, Juni 2021

Journal of Information System, Informatics and Computing

Website/URL: http://journal.stmikjayakarta.ac.id/index.php/jisicom

Email: jisicom@stmikjayakarta.ac.id ,jisicom2017@ gmail.com

16/j.matlet.2019.127252\%0Ahttp://dx.doi.o.

[2] J. Awali, I. Ismail, O. Aryatama, Y. Triana, and W. Asih, "Pelatihan Daur Ulang Logam (Alumunium) bagi Masyarakat Karang Joang,” J. Pengabdi. Kpd. Masy., vol. 4, no. 1, p. 1, 2018, doi: 10.22146/jpkm.30313.

[3] E. Nofiyanti et al., "JAMAIKA : Jurnal Abdi Masyarakat Program Studi Teknik Informatika Universitas Pamulang PELATIHAN DAUR ULANG SAMPAH PLASTIK MENJADI SOUVENIR JAMAIKA : Jurnal Abdi Masyarakat Program Studi Teknik Informatika Universitas Pamulang,” pp. 105-116.

[4] N. Fauzi, K. Udyani, D. R. Zuchrillah, and F. Hasanah, "Penggunaan Metode Elektrokoagulasi Menggunakan Elektroda Alumunium dan Besi pada Pengolahan Air Limbah Batik,” pp. 209-214, 2019.

[5] S. Nani and S. Selvi, "Peran Bank Sampah dalam Meningkatkan Pendapatan Ibu-Ibu Desa Pentadu Barat Kecamatan Tilamuta Kabupaten Boalemo," J. Ilm. Pangabdhi, vol. 5, no. 2, pp. 143-154, 2019, doi: 10.21107/pangabdhi.v5i2.6199.

[6] L. Biati, "Pemanfaatan Limbah Ampas Tahu Menjadi Nilai," 2018.

[7] J. Student, T. Sipil, and L. Belakang, "Evaluasi Perhitungan Material Dan Biaya Besi Pada Proyek,” vol. 1, no. 2, pp. 82-86, 2020.

[8] S. Ibu, D. Menggunakan, and P. H. P. Dan, "No Title,” vol. 1, no. 2, pp. 104-117, 2020.

[9] Y. Septiani, E. Arribe, and R. Diansyah, “( Studi Kasus : Mahasiswa Universitas Abdurrab Pekanbaru ),” vol. 3, no. 1, pp. 131-143, 2020.

[10] “No Title,” vol. 2, no. 2, 2019.

[11] "Efektivitas Penurunan Kadar Besi (Fe) pada Air Sumur dengan Filtrasi Serbuk Cangkang Kerang Variasi Diameter Serbuk Intan Noer Auliah," vol. 10, pp. 25-33, 2019.

[12] A. Qanita, “Analisis Strategi Dengan Metode Swot Dan Qspm (Quantitative Strategic Planning Matrix): Studi Kasus Pada D'Gruz Caffe Di Kecamatan Bluto Sumenep,” J. Ilm. Manajemen, Vol. 1 No. 2, Oktober 2020, vol. 53, no. 9, pp. 1689-1699, 2020.

DOI: $10.52362 /$ jisicom.v5i1.388

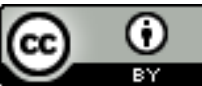

Ciptaan disebarluaskan di bawahLisensi Creative Commons Atribusi 4.0 Internasional. 